Journal of Money and Economy

Vol. 15, No. 3, Summer 2020

pp. $295-312$

DOI: $10.2952 /$ jme.15.3.273

Original Research Article

\title{
Estimating Electric Power's Equivalent Scale for the Urban Iranian Household
}

\author{
Aliasghar Salem* \\ Mitra Amini ${ }^{\text {t }}$ \\ Ali Faridzad ${ }^{\dagger}$ \\ Received: 8 Aug $2020 \quad$ Approved: 6 Feb 2021
}

The household equivalent scale is an index to measure the impact of household demographic characteristics, such as the householder's age and gender, the number of household members, etc. It plays a significant role in measuring poverty and inequality. By taking into account demographic characteristics differences, this index facilitates the reasonable comparison of households' welfare and functions as a coefficient for the target household with a reference household.

Using income and expenditures data of Iranian urban households in 2012-2018, this study measures the relative child cost of each urban household in Iran while estimating the Quadratic Almost Ideal Demand System (QAIDS) and price scaling utilizing Nonlinear Seemingly Unrelated Regression. This model provides significantly more accurate and efficient estimates than the linear model. Also, it calculates the elasticity of income and price of electric power goods. The results illustrate that the relative child cost in Iranian urban households is $33 \%$ of an adult cost, and electric power in Iranian urban households is a necessary yet low elasticity commodity. Therefore, pricing policies may not significantly influence the demand for this product.

Keywords: Economies of Scale, Equivalent Scale, Household Welfare, Quadratic Almost Ideal Demand System, Consumption Economies of Scale, Demographic Characteristics, Micro Data, Child Cost

JEL Classification: D12, C33, Q25

\section{Introduction}

Energy carriers are essential thanks to their vital role in the economic development and advancement of countries, especially developing countries.

\footnotetext{
* Department of Economics, Allameh Tabataba'i University, Tehran, Iran; salem206@yahoo.com

$\dagger$ Department of Energy, Agriculture and Environmental Economics, Allameh Tabataba'i

University, Tehran, Iran; faridzadali@yaho.com

$¥$ Department of Economics, Allameh Tabataba'i University, Tehran, Iran;

mitraamini560@gmail.com (Corresponding Author)
} 
One of the key sectors that is a major consumer of energy is the household sector. The household sector in Iran accounts for approximately one-third of the final energy consumption. According to the latest Energy Balance Sheets data (2016), the per capita electricity consumption per household was about $2858.9 \mathrm{kWh}$ in 2016, indicating a $3.4 \%$ rise compared to the previous year. This trend demonstrates that electric power consumption, and consequently, the per capita consumption of each household have increased. This consumption rate mainly relates to lighting, home appliances, and cooling devices, which are rapidly expanding due to increasing numbers of consumers, change of their lifestyles, and the increasing tendency of Iranians to use electrical appliances in all aspects of their lives. Since consumption is a key concept in macroeconomics and is one of the significant components of GDP and household budget, it can play an important role in improving the quality of life and welfare of individuals in the community (Ghadiri Asl, 2001; Seifi et al. 2009). Consumption and consumer behavior constitute a key part of the microeconomic area, and socio-cultural factors influence the consumption pattern and consumption behavior of urban households. Such factors gain greater significance as households are different in terms of size, age composition (the number of children and adults), levels of education, and other characteristics. In general, households with different features are expected to have dissimilar consumption patterns, and the impact of these characteristics on household demand patterns is as significant as the effect of changing prices and budgets.

Social variables are so significant that if ignored in studies, will indicate that households with different characteristics have not been differentiated, thus resulting in erroneous calculations. Some of these variables include householder's gender, age, and level of education, number of household members, and in particular, the addition of a new member to the household. It is an important phenomenon that is examined under the title of economies of scale resulting from scaling in consumption. It has a special place in the welfare economy, is a significant part of it, and has opened a new horizon in this field. Economies of scale, more specifically, are the result of the scale of a phenomenon in which per capita cost establishes a certain level of living, and as the household dimension expands, it may decrease (Nelson, 1988). This concept derives from the shared consumption of public goods in the family, meaning that to maintain a standard of living, it is not necessarily essential to increase consumption proportionally to population growth (Deaton and Paxton, 1998; Vernon, 2004). Therefore, the main question is: how electric 
power costs will change with the addition of a child? To answer this question, this study uses household budget micro-data in the framework of QAIDS, taking into account the social variables in addition to economic variables. Finally, it examines the existence or non-existence of economies of scale. Accordingly, the present study is organized in the following sections. Section two reviews the existing literature in this area. Section three deals with empirical and theoretical studies on estimating electric power demand function and economies of scale in Iran and foreign countries. Section four empirically estimates the electric power demand function of urban households and the impact of socioeconomic variables and economies of scale on consumption, using QAIDS over a six-year period of 2012-2018. The final section presents the conclusion and the results.

\section{Theoretical Foundations}

This part of the study consists of two sections, including equivalent scale and economies of scale, and the introduction of QAIDS.

\subsection{Equivalent Scale and Economies of Scale}

Households are usually very different due to their different characteristics, ultimately affecting their consumer behavior and preferences. Normally, they choose a basket of goods that is preferred over other goods and that they can purchase. They maximize their utility function, which starting point in economics is the rational consumer behavior and is shown as $\mathrm{u}=\mathrm{U}(\mathrm{q}, \mathrm{s})$, in relation to their budget constraint. In this utility function, the consumption rate is $\mathrm{q}$, consumer goods are $\mathrm{n}$, and the vector of the household characteristics variable is s. Household maximizes the utility function above with the specified budget constraint defined as $\mathrm{x}=\mathrm{pq}$. This solution yields a vector of Marshall demand function as $\mathrm{q}=\mathrm{g}(\mathrm{I}, \mathrm{p}, \mathrm{s})$. Given the disposable income, the prices and properties of the household determine q optimal basket, and by placing Marshall demand functions in $\mathrm{U}(\mathrm{q}, \mathrm{s})$ utility function, the $\mathrm{u}=\mathrm{V}(\mathrm{I}, \mathrm{p}, \mathrm{s})$ indirect utility function is obtained. Finally, by reversing the indirect utility function, the cost function is achieved. Another solution is to minimize $\mathrm{x}=\mathrm{pq}$ cost relative to the utility. The answer to this minimization is Hicksian's demand function, which is a function of utility, prices, and household characteristics. By placing this function at $\mathrm{x}=\mathrm{p}$.q cost, the cost function (expenditure) of $\mathrm{C}=\mathrm{c}(\mathrm{u}, \mathrm{p}, \mathrm{s})$ is obtained. Therefore, the expenditures function $\mathrm{C}=\mathrm{c}(\mathrm{u}, \mathrm{p}, \mathrm{s})$ is equal to the minimum expenditures required by a household with the properties of $s$ necessary to achieve the level of utility $u$ with the level of $p$ prices. 
Since households with different demographic characteristics are found in the community, it is necessary to incorporate these features for accurate and precise welfare comparisons. One of the solutions that may seem appropriate in the first place is to divide household expenditures by the number of individuals and introduce per capita expenditures as a symbol of welfare. It, however, is only effective when all households are assumed to have the same level of allocation while it is not the case in reality, and if done so, the economics of scale have been ignored. Communal life may lead to economies of scale. Economics has usually been concerned with economies of scale in production. Such a phenomenon is also important for consumption, leading to inaccurate estimates if neglected. Economies of scale (scale economies) are derived from three sources (Nguyen, Ha-Duong 2017):

1) They can result from the yield of home products such as cooking.

2) They can be caused by major purchases because as the size of the household increases, the demand for goods and services rises, too, and the family may receive discounts for purchasing large quantities of goods and services.

3) They may be the result of public goods consumption in which one family member's consumption does not impair the consumption of other family members.

Public goods, such as lighting or cooling and ventilation apparatus, for example, can be shared between two or more members of the family, thereby reducing the per capita cost of goods as the household size increases. As noted above, however, household differences are also important and influential in consumption patterns to the extent that the cost of fulfilling the same level of welfare varies for different households. Furthermore, since nominal incomes are not decent indicators of household welfare, the equivalent scale adjusts household consumption patterns using demographic characteristics. It provides a moderate context of welfare comparison for different households in terms of demographic characteristics. Thus, the equivalent scale for two households with $S_{0}$ and $S_{1}$ properties, and the household with $S_{0}$ properties as a reference is calculated as the following:

$m_{r}^{S}=\frac{c\left(u, p, s_{1}\right)}{c\left(u, p, s_{0}\right)}$

Engel (1895) was the first scholar to introduce the concept of an equivalent scale and considered the household food budget representative of household welfare (Deaton \& Muellbauer, 1986). Based on this, he put forward a theory according to which poorer families spend a greater proportion of their total 
expenditures on food supply. He also maintained that the household budget in food could adequately represent the welfare of households of different sizes and compositions (Kamali, 2014). This claim, sometimes referred to as the second law of Engel, has been used as a basis for measuring economies of scale, and while introduced as the Engel approach, has been widely applied in household economics of scale. Rowntree (1901) estimated an equivalent scale based on the minimum nutritional needs, rent, and allowance for miscellaneous household expenditures, and considered the equivalent scale of an adult couple as 100. In 1941, Rothbarth presented a method similar to that of the Engel. In his method, Rothbarth assumed that the share of adult goods in the household budget constitutes the welfare variable. He argued that households with a larger share of adult goods in total household expenditures enjoyed a higher level of welfare, and this share would decrease with the birth of a new child. When a child is added to the household, it is expected that the consumption of adult goods at the same level of primary income decreases, resulting in less welfare (Mirmohammad Alitajrishi, Mohammadi \& Salem 2018). As such, a household with a child consumes less adult goods than a family without a child, and therefore, a household with a child demands a higher income to enjoy the same welfare level.

Barten's (1964) model is a recognizable extension of Engel's model (Mok, Maclean \& Dalziel 2011). Still, the cost function operates in such a way that household composition change alters not only absolute prices but also relative prices. According to Barton's analysis, having a child in the household would make goods, such as ice cream, milk, etc. more expensive than other goods. That is why his analysis is known as a particular goods analysis. Ranjan Ray (1983) suggests a method to consider changes in economies of scale relative to prices. In his article in 1998, Ranjan Ray introduces Engel's scale, which is based on the following demand equation and is estimated as budget share as follows:

$w_{f}=\alpha_{f}+\beta_{f} \log x+\gamma_{f 1} n_{1}+\gamma_{f 2} n_{2}+u_{f}$

where $\mathrm{n} 1$ is the number of adults, $\mathrm{n} 2$ the number of children (1-17 years old), $x$ the total household expenditures, $u$ the error, and $f$ the "food" item. Following Ranjan Ray (1998) to take prices into account, this study expands the above equation to include price changes as follows: 
$w_{f}=\alpha_{f}+\beta_{f} \log (x / p)+\gamma_{f 1} n_{1}+\gamma_{f 2} n_{2}+u_{f}$

where $\mathrm{P}$ is a total price index. The above equation, which determines the budget share linearly, can be expanded to incorporate the reaction of nonlinear expenditures through a second-degree equation as follows:

$w_{f}=\alpha_{f}+\beta_{f 1} \log (x / p)+\left[\beta_{f 2} \log (x / p)\right]^{2}+\gamma_{f 1} n_{1}+\gamma_{f 2} n_{2}+u_{f}$

This second-degree equation includes prices as well as the two age groupings of 1-17 and 17 and higher.

In his article, Ray examines a relationship known as the general household equivalent scale. In this method, he also considers the changes of equivalent scale relative to price changes, illustrating it with $\mathrm{m}_{\text {oh: }}$

$c_{h}(u, p, z)=m_{o h}(u, p, z) c_{R}(u, p)$

where $c_{R}$ is the cost function of the reference household, $c_{h}$ is the cost function of household $\mathrm{h}$, and $\mathrm{z}$ is the number of children. In a more comprehensive account in 1983, Ray introduces a method called price scaling. In his later studies, he presents the public equivalent scale independent from the utility in which nah is the number of adults, and $\mathrm{z}_{\mathrm{h}}$ is the number of household children as follows:

$m_{o h}(p, z)=\left(n a_{h}+\rho z_{h}\right) \prod_{k} p_{k}^{\delta_{k z}} \prod_{k} p_{k}^{\emptyset_{k z}}$

where $\delta$ and $\varnothing$ indicate equivalent scale changes compared to the prices. In the above equation, $\rho$ is the equivalent scale calculated after the estimation of the demand system. The above relation for the base year in which prices are assumed to be one is as follows:

$m_{o h}=\left(n a_{h}+\rho z_{h}\right)$

Experimental studies have demonstrated that it is difficult yet absolutely important in economies of scale to distinguish the impact of household dimension from the household composition. As household demand is expected to vary not only because of the economic scale but also because of different preferences and needs of household members, ranging from infants to grandparents (Nelson, 1988). Two solutions have been proposed to solve this problem. The first one is to assume that all family members have the same preferences. Nelson's study in its experimental section (1988) only examines adult households aged 35-55 years old and does not examine the impacts of household composition factors. The second solution is to include household 
composition variables with different age categories in the model (Deaton and Paxon, 1998; Aitken, Ironmonger, and Erbas, 1995). The advantage of this solution is that preferential differences between age groups can be taken into account.

\subsection{Quadratic Almost Ideal Demand System}

Quadratic Almost Ideal Demand System, an extended model of AIDS, was first introduced by Gorman (1981), and then completed in 1997 by the Bank, Blundell, and Lewbel. Bank et al. presented it with an emphasis on Engel's nonlinear curve at the micro-data level, using quadratic logarithm form and socioeconomic characteristics of the households. These two models are one of the most popular patterns for estimating system demand, which are still consistent with consumer theory, and a quadratic condition is added to it to overcome cost flexibility constraints (Mir, Yu, Abler, Philips, 2014) as follows:

$w_{i}=\alpha_{\mathrm{i}}+\sum_{\mathrm{j}=1}^{\mathrm{n}} \gamma_{\mathrm{ij}} \ln \mathrm{p}_{\mathrm{j}}+\beta_{\mathrm{i}} \ln \left[\frac{\mathrm{m}}{\alpha(\mathrm{p})}\right]+\frac{\lambda_{\mathrm{i}}}{\mathrm{b}(\mathrm{p})}\left\{\ln \left[\frac{\mathrm{m}}{\alpha(\mathrm{p})}\right]\right\}^{2}+\sum_{\mathrm{j}=1}^{\mathrm{n}} \delta_{\mathrm{ij}} \mathrm{h}_{\mathrm{j}}$

$\ln \alpha(\mathrm{p})=\alpha_{0}+\sum_{\mathrm{i}=1}^{\mathrm{n}} \alpha_{\mathrm{i}} \log \mathrm{p}_{\mathrm{i}}+1 / 2 \sum_{\mathrm{i}=1}^{\mathrm{n}} \sum_{\mathrm{j}=1}^{\mathrm{n}} \gamma_{\mathrm{ij}} \log \mathrm{p}_{\mathrm{i}} \mathrm{p}_{\mathrm{j}}$

$\mathrm{b}_{(\mathrm{p})}=\prod_{\mathrm{i}=1}^{\mathrm{n}} \mathrm{p}_{\mathrm{i}} \beta_{\mathrm{i}}$

If in the above relation $\lambda_{\mathrm{i}}$ equals zero, QAIDS will turn into the AIDS model. It, therefore, can be used to identify QAIDS or AIDS models specifically. The model specification is carried out based on the significance test of $\lambda_{\mathrm{i}} \mathrm{s}$ (Pakdaman), and if $\lambda_{\mathrm{i}}$ is significant, QAIDS will be superior to AIDS.

In this model, too, all former constraints are applied to the parameters to adapt the extracted demand function to the Consumer Theory.

To achieve the objectives of this study, it is assumed that the utility function exists for households, and this utility function follows the demand theory. Since the decision making process in households is complex and in addition to economic factors, other factors are also important in this process, this study, in its experimental modeling, in addition to economic variables such as price and household income, $\mathrm{p}_{\mathrm{j}}, \mathrm{y}$ and $\mathrm{P}$ represent goods' prices, households' income respectively, other household properties such as literacy, age, gender, etc. are also considered Because each feature of the household can have a positive or negative effect on the demand of that household, and this doubles the importance of the issue for higher accuracy in the analysis, this variable is shown by $h j$. 
Besides, $\alpha_{i}, \gamma_{i j}, \delta_{i j}$, and $\beta_{i}$ are the model parameters. $\gamma_{i j}$ represents the percentage of change in the share of the budget allocated for the purchase of $i$ goods as a result of a one-percent change in the price of $j$ goods while assuming all other factors constant. $\beta_{i}$ indicates the percentage of change in $\beta$ in the share of the goods' expenditure related to $i$ goods due to change in real spending expenditures, and assuming all other factors constant. $\beta_{\mathrm{i}}$ represents the percentage of change in the share of goods' expenditures of the i goods due to change in the real income, assuming the constancy of relative prices. If, in this case, the goods are luxury-normal, $\beta_{\mathrm{i}}$ is positive, and if the goods are necessary, it will be negative.

To adapt the extracted demand function to the consumer theory, the following constraints must be set for the parameters in both patterns:

1) The "adding-up" condition ensures that the expenditure shares always sum up to one $\left(\sum w_{i}=1\right)$. This condition is fulfilled if

$\sum_{\mathrm{i}=1}^{\mathrm{n}} \alpha_{\mathrm{i}}=1, \quad \sum_{\mathrm{i}=1}^{\mathrm{n}} \gamma_{\mathrm{ij}}=0, \quad \sum_{\mathrm{i}=1}^{\mathrm{n}} \beta_{\mathrm{i}}=0$

2) The "homogeneity" condition guarantees that there is no "money illusion," i.e., if all prices and income change by the same rate (e.g., when a new currency like the EURO is introduced, the consumed quantities do not change. It is fulfilled if

$\sum_{\mathrm{j}=1}^{\mathrm{n}} \gamma_{\mathrm{ij}}=0$

3) The "symmetry" condition follows from applying Shepard's Lemma to the expenditure function of AIDS (1). It can be derived directly from the definition of the $\gamma \mathrm{s}$, which can be found below equation (2):

$\gamma_{\mathrm{ij}}=\gamma_{\mathrm{ji}}$

own price and income elasticity in the QAIDS model are obtained by differentiating budget share equations, which are summarized based on the Bank's (1977) relationship: 
$\mathrm{e}_{\mathrm{ij}}^{\mathrm{u}}=\frac{\mu_{\mathrm{ij}}}{\mathrm{w}_{\mathrm{i}}}-\delta_{\mathrm{ij}}$

$\mathrm{e}_{\mathrm{i}}=\frac{\mu_{\mathrm{i}}}{\mathrm{w}_{\mathrm{i}}}+1$

Where $e_{i j}^{u}$ is the Marshall price elasticity and $e_{i}$ is the income elasticity. It is also the $\delta_{\mathrm{ij}}$ delta of Kraniker. If $\mathrm{i}=\mathrm{j}$ is $\delta_{\mathrm{ij}}=-1$ and otherwise $\delta_{\mathrm{ij}}=0$. Also $\mu_{\mathrm{i}}$ and $\mu_{\mathrm{ij}}$ are calculated as follows:

$\mu_{\mathrm{i}}=\frac{\partial \mathrm{w}_{\mathrm{i}}}{\partial \ln \mathrm{m}}=\beta_{\mathrm{i}}+\frac{2 \lambda_{\mathrm{i}}}{\mathrm{b}(\mathrm{p})}\left\{\ln \left[\frac{\mathrm{m}}{\mathrm{a}(\mathrm{p})}\right]\right\}$

$\mu_{i j}=\frac{\partial w_{i}}{\partial \ln p_{j}}=\gamma_{i j}-\mu_{i}\left(\alpha_{j}+\sum_{k} \gamma_{j k} \ln p_{k}\right)-\frac{\lambda_{i} \beta_{j}}{b(p)}\left\{\ln \left[\frac{m}{a(p)}\right]\right\} 2$

\section{Review of Empirical Studies}

It is attempted in this section to summarize some of the important studies carried out in Iran and abroad to estimate the electric power demand function, the economies of scale, and modelings similar to AIDS and QAIDS and their results.

\subsection{International Studies}

In their study, Phipps and Garner used the US and Canada's expenditure data from 1986 to 1988 and examined the equivalent scale using Engel's approach while considering three essential baskets of goods for households. The results of their study demonstrated that the equivalent scale of the two countries is not significantly different. Van de Ven (2003) compared different methods of measuring equivalent scales, including the four methods of Engel, Rothbart, demand system including demographic characteristics and price effects, using data related to household expenditures. He believed that although there are biases regarding other methods of measuring the equivalent scale, the demand system method, which employs combined data is the reference method for estimating the equivalent scale. The result is as follows: based on the estimation result gained using Engel's method, household expenditures' increase is higher in Australia compared to Britain due to childbirth, whereas Rothbart's model supports the reverse. In both countries, there are significant economies of scale due to the size of the household. The equivalent scale estimated using the demand system indicates significant economies of scale in both countries. The difference between child and adult cost in the demand system method is lower than that of the Engel and Rothbart's methods. Gary (2005), in his study, summarizes the different methods used to calculate and 
estimate child costs. He believes that none of the methods of estimating child costs is completely satisfactory. In his paper, he calculates equivalent scale and child cost by measuring validated methods' means, and the results show that as the child ages, his costs increase.

Gibson and Bangon (2007) examined the relationship between household dimensions and food demand. In her study, Takeda estimated the equivalent scale for Russian households for years 1994 and 2002, which are related to the economic crisis in the country, using subjective economic welfare, Engel's approach, and the ordinary least squares method. The results of her study demonstrated that after the crisis, the equivalent scale changed, but the number did not create much change for the extra adult.

Parpiev and Yusupov (2011) examined the relationship between economies of scale and consumption in Uzbekistan. They categorized household expenditures into food groups, meals, clothing, education, health, transportation, and shelter. They categorized individuals into five age groups and male and female categories. Their results showed economies of scale in meals, clothing, education, health, transportation, and shelter. In his study, Vashchilko (2014) estimated an equivalent scale for Belarusian households, taking into account the economies of scale resulting from household size. He used a price-scaling approach to study poverty and inequality in the country in the years 2006 and 2020 in this country in five goods groups. Results showed that poverty declined by $50 \%$ during this period, and this reduction occurred in male-headed households, female-headed households, and singlechild households.

\subsection{National Studies}

Khalaji et al. (2007) addressed the concept of household equivalent scale to different social characteristics of households and presented the impact of these characteristics on household consumption patterns using time series data from 1985 to 2004 as well as cross-sectional data for 2003. Finally, they calculated household equivalent scales. The results showed a large expenditure gap between the city and the village, which could be due to lower costs and the production of self-consumption goods in the villages. This difference between urban and rural households decreases as household size and householder's age increases. Farzad (2010), in his master's thesis, extracted an equivalent scale using Rothbart's method for households living in Tehran in 2008 and measured one child's expenditure compared to the total household expenditure. Finally, he determined equivalent household scales for adult goods. Using this method, he first conducted a reparability test for adult goods 
by specific age group, and then calculated the household equivalent scale and the relative child cost, taking into account different household characteristics with the reference household. The results showed that as the size of the household grows and the relative child cost of children between 0 and 13 years of age increases relative to total costs, the amount of equivalent scales increases for adults. Shafiei (2012) measured the equivalent scale of Iranian urban households in 2009, using Deaton and Muellbauer's method, and taking into account the household dimension characteristics, age of children, and area of residence of each household relative to the reference household (childless couple). Using QAIDS and the 3SLS methods, the calculations of economies of scale and composition of Iranian urban households were conducted. The results showed that in Iran in 2007, representing a childless couple with number 100 , the addition of one child would definitely increase this number, and the addition of a 0-6-year-old child, a 7-12-year-old child, and a 13-18 year-old-child resulted in numbers 124, 113, and 129, respectively. Zamanzadeh and Shahmoradi (2014) calculated an equivalent scale based on household utility function and used Iranian household expenditure data in 2008 for households with different income deciles. Their study showed that an equivalent scale to varying levels of income is different and increases with the relative household income raise. It demonstrates that in low-income households, family members' participation in goods consumption is high, and as household income increases, their participation and economies of scale in household consumption decreases. Therefore, the equivalent scales of households with higher income levels are larger than those of lower-income households.

This study estimated the equivalent scale of electricity in Iran using the QAIDS model, which can differentiate this study from others.

\section{Statistical Bases, Research Variables, Model Estimation, and Interpretation of Experimental Results}

Appropriate subordinate form, type of indices, number of data, and proper estimation method effectively obtain accurate and unbiased estimates. This study used the subordinate form of QAIDS, and to achieve the goals of this study and its greater accuracy, cross-sectional data have been used for the period 2012- 2018, which is in the form of 131408 urban households $(475,355$ people in total). These data are collected from the Household Expenditure and Income Survey collected by the Statistics Center. This microdata includes the price indices of goods' groups in different urban areas of each province. 
The family expenditure and income survey extensively include information on urban and rural households, and urban household information were used in this study. Some demographic characteristics of households are briefly given in the following table:

Table 1

Demographic Characteristics of Households

\begin{tabular}{|l|l|l|l|l|l|}
\hline & Min & Max & Average & variance & $\begin{array}{l}\text { standard } \\
\text { deviation }\end{array}$ \\
\hline Householder's Gender & 0 & 1 & 0.87 & 0.1080879 & 0.328767243 \\
\hline $\begin{array}{l}\text { Householder's education } \\
\text { years }\end{array}$ & 0 & 24 & 7.1 & 25.995255 & 5.09855424 \\
\hline Householder's age & 14 & 99 & 49.49 & 223.28115 & 14.94259528 \\
\hline $\begin{array}{l}\text { Householder's activity } \\
\text { status }\end{array}$ & 0 & 1 & 0.65 & 0.2272784 & 0.476737314 \\
\hline Income (Rial) & 1800000 & 6460340200 & 203381021.9 & $2.77895 \mathrm{E}+16$ & 166701911.5 \\
\hline Electric power price & 100 & 154.3895 & 124.44 & 454.2644 & 21.31348 \\
\hline Price of other energies & 100 & 123.7464 & 113.0913 & 116.9249 & 10.81318 \\
\hline
\end{tabular}

Reference: research findings

\section{Model Estimation and Research Pattern Procedures}

The estimation of this study is a nonlinear estimation of QAIDS, and the Nonlinear Seemingly Unrelated Regression (NLSUR) method is used. QAIDS is nonlinear and is often linearized by recourse to the Stone price index, which can then be easily estimated by (NLSUR) technique. This practice has contributed to the popularity of the QAIDS model but is recently found to yield bias, inconsistency, and inefficiency in parameter estimation and other problems. (Pashardes, 1993; Alston et al., 1994; Buse, 1994, 1995; Moschini, 1995). Therefore, nonlinear methods have been used to be accurate in estimation as well as an unbiased, consistent, and efficient parameter. Furthermore, the coefficients are estimated using Stata software. NLSUR is a system of nonlinear equations that, other than disturbance, are correlated with one another. These regressions provide a system of nonlinear equations using Feasible Nonlinear Generalized Least Squares (FGNLS). These models have numerous applications and can be used for different household demand functions for given goods. In this model, the electricity demand function is considered using the equivalent scale, and the changes of equivalent scale are estimated by price changes. When $\rho$ is calculated, an equivalent scale with the base year is obtained. In this model, too, households are divided into two groups of children and adults, and the pattern used in the study is as the following subordinate form: 
$w_{i h}=\alpha_{i}+\delta_{i} z_{h}+\sum_{j} \gamma_{i j} \ln p_{j}+\beta_{i}\left[\ln x_{h}-\alpha_{0}-\sum_{k} \alpha_{k} \ln p_{k}-\right.$

$\frac{1}{2} \sum_{i} \sum_{j} \gamma_{i j} \ln p_{i} \ln p_{j}-\ln \left(n a_{h}+\rho z_{h}\right)-\sum_{k} \varphi_{k} n a_{h} \ln p_{k}-$

$\left.\sum_{k} \delta_{k} z_{h} \ln p_{k}\right]+\lambda_{i} \prod_{k} p_{k}^{-\beta_{k}}\left[\ln x_{h}-\alpha_{0}-\sum_{k} a_{k} \ln p_{k}-\right.$

$\frac{1}{2} \sum_{i} \sum_{j} \gamma_{i j} \ln p_{i} \ln p_{j}-\ln \left(n \alpha_{h}+\rho z_{h}\right)-\sum_{k} \varphi_{k} n \alpha_{h} \ln p_{k}-$ $\left.\sum_{k} \delta_{k} z_{h} \ln p_{k}\right]^{2}+\sum_{\mathrm{j}=1}^{\mathrm{n}} \delta_{\mathrm{ij}} \mathrm{h}_{\mathrm{j}}$

Following Ray and Mishra (2011), the price scaling model of QAIDS was used to combine the Quadratic Ideal Demand System and the price scaling method. Here, $w_{i h}$ represents the share of the budget for goods $i$ for household $h, x_{h}$ is the total expenditures of household $h$, and $h_{j}$ is the social variables, including gender, householder's years of education, age, and activity status. In the model, all constraints of homogeneity, symmetry, and integration on parameters are considered, and the estimations of QAIDS and the calculation of the electricity elasticity are shown in Tables 1 and 2, respectively: 
Table 2

Quadratic Almost Ideal Demand System Estimation

\begin{tabular}{|l|l|l|}
\hline Coefficients & Estimates & $\mathrm{P}>|\mathrm{Z}|$ \\
\hline Intercept $\left(\alpha_{i}\right)$ & 0.183067 & $(0.000)$ \\
\hline Electric power price $\left(\gamma_{i j}\right)$ & -0.00275 & $(0.005)$ \\
\hline Price of other energies $\left(\gamma_{i j}\right)$ & -0.0007374 & $(0.000)$ \\
\hline Real household income $\left(\beta_{i}\right)$ & -0.01855 & $(0.000)$ \\
\hline $\begin{array}{l}\text { Squared Real Household } \\
\text { Income }\left(\lambda_{i}\right)\end{array}$ & 0.00044 & $(0.000)$ \\
\hline Gender $\left(h_{j}\right)$ & -0.00044 & $(0.059)$ \\
\hline Age $\left(h_{j}\right)$ & 0.0000414 & $(0.000)$ \\
\hline $\begin{array}{l}\text { Householder's education } \\
\text { years }\left(h_{j}\right)\end{array}$ & -0.00010 & $(0.000)$ \\
\hline $\begin{array}{l}\text { Householder's activity status } \\
\left(h_{j}\right)\end{array}$ & -0.000466 & $(0.016)$ \\
\hline $\begin{array}{l}\text { Relative cost of extra child } \\
\text { in relation to adult } \\
(\rho)\end{array}$ & 0.33 & $(0.000)$ \\
\hline $\begin{array}{l}\text { Equivalent scale's sensitivity } \\
\text { to price }\left(\emptyset_{1}\right)\end{array}$ & 2.346 & $(0.000)$ \\
\hline $\begin{array}{l}\text { Equivalent scale's sensitivity } \\
\text { to price }\left(\emptyset_{2}\right)\end{array}$ & -1.5715 & $(0.000)$ \\
\hline $\begin{array}{l}\text { Equivalent scale's sensitivity } \\
\text { to price }\left(\emptyset_{2}\right)\end{array}$ & -0.7925 & $(0.000)$ \\
\hline $\begin{array}{l}\text { Equivalent scale's sensitivity } \\
\text { to price }\left(\delta_{2}\right)\end{array}$ & -0.002981 & $(0.000)$ \\
\hline $\begin{array}{l}\text { Equivalent scale's sensitivity } \\
\text { to price }\left(\delta_{2}\right)\end{array}$ & -0.00395 & $(0.000)$ \\
\hline Refrence: & & \\
\hline
\end{tabular}

Reference: research findings

Table 3

Income and Price Elasticities

\begin{tabular}{|l|l|l|l|ll|}
\hline Goods Groups & $\begin{array}{l}\text { Average share } \\
\text { of goods }\end{array}$ & $\begin{array}{l}\text { Income } \\
\text { Elasticity }\end{array}$ & $\begin{array}{l}\text { Marshall Price } \\
\text { Elasticity }\end{array}$ & $\begin{array}{l}\text { Compensatory Price } \\
\text { Elasticity }\end{array}$ & \\
\hline Electric Power & 0.016 & 0.77 & -0.23 & -0.21 \\
\hline
\end{tabular}

Reference: research findings

\section{Interpretation of the Results}

The results presented in Table 1 are related to the estimation of simultaneous equations system for households' budget using seemingly unrelated nonlinear regressions and show that the coefficients are highly significant for urban 
households. It indicates good fitting in the estimated equations, and to apply the aggregation constraint to the budget share equations, one of the budget share equations was eliminated. Model price coefficients include $\alpha_{i}$, which indicates the relationship between goods prices and households' budget shares or, in other words, household demand. $\beta_{i}$ is the real income coefficient, i.e., the income that is segmented on the price index. $\gamma_{i j}$ represents the cross and own price coefficients such that own price coefficients demonstrate the demand changes of group 1 (electricity) relative to that group's price, and cross-price coefficients display the first group's changes compared to the price change of the second group. Also, $\emptyset_{1}, \emptyset_{2}$ and $\emptyset_{3}$ are adult coefficients while $\delta_{1}$ and $\delta_{2}$ are the child-related coefficients in this model. These coefficients determine the sensitivity of the equivalent scale in relation to the price changes obtained for urban households with high significance in this study, indicating that the equivalent scale changes with prices. Ranjan Ray proposed this as equivalent scale characteristics. $\rho$ coefficient is the relative cost of the extra child in relation to the adult, its scale is normalized relative to one, and its value for urban households is $33 \%$. $\lambda_{i}$ coefficients are the second-order coefficients that represent the second-order effects of expenditure on the budget share. These coefficients are significant for urban households, and it can be argued that they support the existence of second-order effects of expenditure or QAIDS. Based on the results of this table, among the variables considered in the system, the variable of householder's gender is the only one that has not been statistically significant in any of the system equations because its probability is more than 0.05 . It, therefore, can be inferred that according to the data and the equivalent scale model, the gender of the householder is one of the factors that is not effective in allocating household budget to the electricity goods group in the household consumption basket. As a result, the impact of the variables of education years and householder's activity status (being employed or not) on the electric power demand of urban households is negative and significant. In other words, as education level and employment status improve, electric power consumption decreases, and as householder's age increases, electric power consumption escalates. One of the reasons may be spending more time at home and, in turn, the increased need to use electrical appliances, such as heating and cooling devices, etc.

Following the assessment and estimation of demand function coefficients, which, due to the impacts of economic policies, have always been the focus of policymakers' attention, Table 2 examines the price and income elasticity for identifying the type of goods. Because these estimates require more precision in determining the specific demand for goods, elasticity calculation 
is required to provide the exact relationship between the fluctuations and how they are estimated. In this section, own-price elasticity and incomes were calculated using the formulas of Section 2. By examining the price elasticity, it was observed that demand price elasticity in the examined goods' group is negative. In none of the groups, the demand law is violated, and they are as expected. Electricity demand price elasticity in urban households in the QAIDS model was $-0.23 \%$, which indicated that assuming all other factors constant, if electric power price increases by 1 percent, its demand will decrease by $23 \%$. Therefore, electric power is low-elasticity goods, and the income elasticity of the goods is $77 \%$. Since the calculated income elasticity of the goods for the whole country is $77 \%$, and this number is less than one, it is considered necessary goods.

\section{Results and Discussion}

Since the equivalent scale is a method of incorporating household demographic characteristics into welfare estimates and measuring poverty and inequality, this study examined the electric power demand function of urban households that comprise a large proportion of consumers, using the NLSUR method for QAIDS for accuracy and efficiency. Next, the economies of scale were analyzed using the equivalent scale. As was illustrated in previous sections, income and price elasticity of electric power demand in urban households is smaller than one. It shows that electric power, as an energy carrier in the Iranian household's consumption basket, is an essential and nonelastic goods, indicating low consumer sensitivity due to the low share of these goods in total household cost. Therefore, pricing policies have a slight impact on household electricity demand. It is better to employ other methods, such as education for using low-cost goods, raising people's awareness of the costbenefit of purchasing these appliances in the future, and instructing conservation in electric power consumption via media, books, and schools, etc. to control its demand rate. Meanwhile, $\rho$ displays the relative cost of the extra child in relation to the adult whose scale is also normalized relative to one, and its value for urban households is $33 \%$.

As mentioned earlier, household dimension impacts household consumption behavior and Brewing (1992) argues that adding a child to the family and subsequently changing the household dimension will affect the household's consumption behavior. Also, the relative cost of a child is estimated to be $33 \%$ of an adult's cost. Being positive and smaller than one indicates an economic phenomenon called "Economies of Scale on Consumption of Goods and Services" in household consumption. Thus, if we 
simply consider greater welfare in terms of more use of goods and services, the existence of economies of scale facilitates the shared consumption of goods and services for people. The shared use of goods and services will increase the capacity to create utility and higher welfare for the consumer, without the need to increase the number of goods and services.

Accordingly, economies of scale in specific optimal consumption emphasizes that with the addition of a new member to the household, either a child or an adult, consumption expenditures change (Mehrjou, Shirvanian, \& Bakhshoodeh, 2017). It is possible that per capita expenditures of each household member reduces in the new situation compared to the former situation, without reducing the household's welfare level. Therefore, economies of scale pave the way for improving the standard of living of each household member (Khalaji et al. 2007; Kakwani \& Son, 2005). Ignoring this as well as the equivalent scale in the calculations of institutions that are responsible for estimating poverty and income distribution cause bias and error. In fact, in such analyses, households with different structures in terms of children and adults are considered similar, which renders welfare and poverty comparisons ineffective. It is, therefore, suggested that future studies take differences in household characteristics and their general household equivalence scale for estimating the welfare impacts of poverty and income distribution into account.

\section{References}

Barten, A. P. (1964). Family Composition, Prices and Expenditure Patterns in: Econometric Analysis for National Economic Planning: 16th Symposium of the Colston Society, S. 277-292, hrsg. v. Hart, P./Mills, G./Whitaker, JK.

Deaton, A. S., \& Muellbauer, J. (1986). On Measuring Child Cost: With Application to Poor Countries. Journal of Political Economy, 94, 720-44.

Deaton, A., \& Paxson, C. (1998). Economies of scale, household size, and the demand for food. Journal of political economy, 106(5), 897-930.

Engel, E. (1895). Die Lebenskosten Belgischer Arbeiter-Familien Fruher and Jetzt, Heinrich.

Ghadiri Asl, B. (2001). Principles of Economics. Sepehr Publishing Center.

Ironmonger, D. S., Aitken, C. K., \& Erbas, B. (1995). Economies of Scale in Energy Use in Adult-Only Households. Energy Economics, 17(4), 301-310.

International Statistical Institue Bulletin, 9.

Kakwani, N., \& Son, H. H. (2005). Economies of Scale in Household Consumption: With Application to Australia. Australian Economic Papers, 44, 134-148. 
Kamali, F. (2014). Household Size, Economies of Scale and Public Goods in Consumption: A Proposal to Resolve the Food Share Paradox, Emory University 1602 Fishburne Dr., Rich Building, Atlanta, GA, 30322, USA.

Khalaji, A., Raghfar, H., \& Mohammadi, T. (2007). The Measure of Household Economies of Scale in Iran. Social Welfare Quarterly, 24.

Mehrjou, S., Shirvanian, A., Bakhshoodeh, M. (2017). Investigating the Economy of Scale in Iranian Rural Households. Agricultural Economics Research, 9(33), 93108.

Mirmohammad Alitajrishi, F., Mohammadi, T., Salem, A. (2018). Comparative Study of the Equivalence Scale for Iranian Urban Households; Before and After Implementation of Targeted Subsidies Plan. Economics Research, 18(70), 1-22.

Mok, T., Maclean, G., \& Dalziel, P. (2011). Household Size Economies: Malaysian Evidence. Economic Analysis \& Policy, 41(2).

Nguyen, H. S., \& Ha-Duong, M. (2017). Family Size, Increasing Block Tariff and Economies of Scale of Household Electricity Consumption in Vietnam from 2010 to 2014. External Economics Review, Foreign Trade University, Hanoi, Vietnam, 2017 (101), 1-11.

Parpiev, Z., \& Yusupov, K. (2011). Testing Household Economies of Scale in Uzbekistan. Eurasian Journal of Business and Economics, 4, 25-51.

Seifi, A., \& Alaei, Kh. (2009). Theoretical Foundations of Consumption Pattern and Its Role in the Country's Economic Development. Export Development Magazine.

Vernon, Victoria (2005). Food Expenditure, Food Preparation Time, and Household Economies of Scale. Unpublished Manuscript, Fashion Institute of Technology, State University of New York 